\title{
Wieder, wider, weiden: casos de parodia y autoparodia en la narrativa de Roberto Bolaño
}

Felipe Adrián Ríos Baeza Benemérita Universidad Autónoma de Puebla

Resumen

Si bien el término parodia ha sido estudiado y signado como un género perdido de la antigüedad, la literatura contemporánea lo vuelve un procedimiento creativo gracias a una de sus aristas más interesantes: la de reiterar. En una novela determinante para su proyecto literario global, Estrella distante (1996), el chileno Roberto Bolaño (1953-2003) parece estar cifrando su obra con esta clave. Es decir, la mencionada novela no sólo estaría contado, en términos textuales, la historia de un piloto de la Fuerza Aérea Chilena llamado Carlos Wieder que, a un tiempo, es un artista y un asesino; sino que en términos transtextuales, y según la explicación de Bibiano O’Ryan (uno de los personajes), el apellido Wieder estaría asociado a una cierta recurrencia en la literatura de Bolańo: la de la parodia como eje mismo, que es simultáneamente burla y reiteración.

Wieder, wider, weiden: decir de nuevo, en contra y de manera perversa. La asociación fonética es, asimismo, asociación creativa. Para Bolaño, el espacio de la parodia le permite reiterar, refutar y pervertir ciertos actos que acometen sus personajes, todos ellos ubicados en una suerte de "eterno retorno" que los hace, una y 
otra vez, asesinar, escribir, hacer el amor, leer, hablar, pensar. Se propone aquí, una hipótesis a comprobar: sólo en el volver a contar, en la repetición de un texto en otro contexto, en la parodia es como realmente se pueden apreciar los énfasis y subrayados que Bolaño desea hacer notorios en su propuesta literaria.

Palabras clave: Roberto Bolaño, parodia, reiteración, frontera.

\section{Abstract}

Even though the term parody has been studied and identified as a lost genre from older times, contemporary literature has turned it into a creative procedure thanks to one of its most interesting facets: reiteration. In a determinant novel for his global literary project: Estrella distante (1996), the Chilean writer Roberto Bolaño (1953-2003) seems to encode his work in this key. In other words, the novel would not only narrate, in literary terms, the history of a pilot of the Chilean Airforce named Carlos Wieder, who, at the same time, is an artist and a murderer; but also in transtextual terms, according to the explanation by Bibiano O'Ryan (one of the characters), the last name Wieder would be associated with a certain recurrence in Bolaño's literature: parody as an axis, becoming, simultaneously, mockery and reiteration.

Wieder, wider, weiden: saying again, against and in a perverse way. The phonetic association is, at the same time, a creative association. For Bolaño, the space of parody allow him to reiterate, refute and distort certain acts done by his characters, all of them located in some sort of "eternal U turn" that makes them, over and over again, kill, write, make love, read, talk, think. This article proposes a hypothesis to be proved: only in that re-telling, in that repetition of one text in a different context and in that parody, can the emphasis proposed by Bolaño in his literary work be appreciated.

Keywords: Roberto Bolaño, Parody, Reiteration, Border. 
En el fondo, la parodia, sólo disfraza

el deseo enorme de ponerse a llorar

ROBerto Bolaño

\section{El eslabón perdido de Aristóteles}

$\mathrm{D}$ esde su propio origen como disciplina, la teoría de la literatura se ha propuesto problematizar un asunto que viene, como casi todo, cifrándose desde la Poética de Aristóteles. ${ }^{1}$ Si a la hora de hablar de los géneros dramáticos el filósofo griego planteaba que la tragedia, en tanto manifestación alta e idealizada, tenía su reverso en la comedia (con la cual se podían burlar los mandatos autoritarios e incluso los designios divinos), a la hora de atender a los géneros narrativos, la épica parece haber recorrido siglos sin su contraparte burlesca o "peyorativa».

¿Cuál es el género narrativo "bajo"? En otras palabras: ¿qué manifestación venía a poner en tela de juicio lo cantado por los rapsodas? Se trata del eslabón perdido que en el plano de la ficción autores como Jorge Luis Borges y Umberto Eco han utilizado como motivo de algunos de sus más reconocidos relatos: "La biblioteca de Babel" y El nombre de la rosa, respectivamente. Este último es un libro que completa la clasificación aristotélica pero que se pierde, o hacen que se pierda, en la historia de las ideas literarias; no obstante, en el plano de la teoría, recientemente se ha intentado reconstruir para hablar de uno de los procedimientos representativos del arte del siglo XX: la posibilidad de volver a presentar, de repetir con otros registros, de - en la lógica postestructuralistatraer a un contexto presente un signo del pasado. El segmento

${ }^{1}$ Para un clarificador recorrido preliminar, puede verse el capítulo "En torno al concepto de parodia", de Elzbieta Sklodowska, incluido en su libro La parodia en la nueva novela hispanoamericana (1960-1985). 
vacío, el reverso "bajo" de la épica es la parodia, entendida, desde la posmodernidad y la intertextualidad, no como un simple género sino como un procedimiento que permea el quehacer creativo de todo artista.

Gérard Genette acierta, en Palimpsestos: la literatura en segundo grado, al decir que si "lo cómico no es otra cosa que lo trágico visto de espaldas" (1989: 26), la estrategia narrativa que le voltea la cara a la épica es eso que se nombra parodia, a ratos de manera muy laxa:

Ôda, es el canto; para: «a lo largo de», «al lado»; parôdein, de ahí parôdia, sería (?) el hecho de cantar de lado, cantar el falsete, o con otra voz, en contracanto - en contrapunto-, o incluso cantar en otro tono: deformar, pues, o transportar una melodía. [...]. En un sentido todavía más amplio, la trasposición de un texto épico podría consistir en una modificación estilística que lo transportaría, por ejemplo, del registro noble que es el suyo, a un registro más coloquial, e incluso vulgar (20-21).

Si la catarsis en la tragedia tenía como función purgar a los ciudadanos de afecciones psicológicas enfermizas, como el temor y la piedad, al pensar que la intención del espectáculo cómico o paródico fue únicamente disuadir o distraer a los individuos, se tendría una conclusión limitada, sobre todo si el escritor cómico por antonomasia era Aristófanes. Si en Lisistrata se ocupa en cómo acabar la guerra que se libra entre insignes hombres patrios, utilizando la amenaza de la abstinencia sexual por parte de sus esposas, y en Las avispas presenta una ridiculización de los oprobios judiciales, el asunto, por supuesto, va más allá de la mera provocación de la risa. La burla a las autoridades aparece como la obligación de todo ciudadano. Los géneros "bajos", entonces, ponen en evidencia las negligencias y las fisuras propias del poder. Tal vez por eso parece lógico que un estudio tan subversivo como el que Aristóteles pudo haber hecho sobre la parodia en su Poética se "pierda" entre los anaqueles de la historia. 
$\mathrm{Al}$ intentar reconstruir el motor de la maquinaria de la parodia, Gérard Genette se cuida de no clasificarla como un simple género, pues, con lo visto, las manifestaciones narrativas actuales excederían el eslabón perdido de Aristóteles. Si se observan sus efectos, la parodia podría cumplir las funciones de una purga (el alivio de tensiones, al tiempo que se realiza una denuncia social); sin embargo, si se pone atención a sus procedimientos, "cantar a un costado", es decir, parodiar, implica escribir a un lado o en el alero de una manifestación anterior, repetirla, resignificarla. En el fondo, todo arte es paródico ya que, aunque no provoque necesariamente la risa, vuelve a cantar algo ya cantado, modulando los enunciados de otro modo.

Esto bien lo sabían escritores como Joyce, Borges y Nabokov, de quienes lo aprendió bien el chileno Roberto Bolaño (19532003). En una novela determinante para su propuesta literaria, Estrella distante, Bolaño parece cifrar su obra en esta clave, por lo que dicha novela no sólo estaría contado, en términos textuales, la historia de un piloto de la Fuerza Aérea Chilena llamado Carlos Wieder que, a un tiempo, es un artista y un asesino, sino que en términos transtextuales, y según la explicación de Bibiano O’Ryan (uno de los personajes), el apellido Wieder estaría asociado a una cierta recurrencia en la literatura de Bolańo: la de la parodia como eje mismo, que es simultáneamente burla y reiteración. Bien vale recuperar la siguiente cita para plantearse que en Estrella distante se anuncia un modo plausible de leer la propuesta narrativa de Bolaño que, junto con la de César Aira, Rodrigo Fresán o Enrique Vila-Matas, se presenta como una de las más arriesgadas en el contexto de la literatura contemporánea en español:

Wieder, según Bibiano nos contó, quería decir "otra vez", “de nuevo", "nuevamente", "por segunda vez", "de vuelta”, en algunos contextos "una y otra vez", "la próxima vez" en frases que apuntan al futuro. Y según le había dicho su amigo Anselmo 
Sanjuán, ex estudiante de filología alemana en la Universidad de Concepción, sólo a partir del siglo XVII el adverbio Wieder y la preposición de acusativo Wider se distinguían ortográficamente para diferenciar mejor su significado. Wider, en antiguo alemán Widar o Widari, significa "contra", "frente a", a veces "para con". Y lanzaba ejemplos al aire: Widerchrist, "anticristo"; Widerhaken, "gancho", "garfio"; Widerraten, "disuasión"; Widerlegung, "apología”, "refutación”; Widerlage, "espolón”; Widerklage, "contraacusación", "contradenuncia"; Widernatürlichkeit, "monstruosidad" y "aberración" [...]. E incluso Weiden también quería decir regodearse morbosamente en la contemplación de un objeto que excita nuestra sexualidad y/o nuestras tendencias sádicas. (Bolaño, 2003: 50-51)

Wieder, wider, weiden: decir de nuevo, en contra y de manera perversa. La asociación fonética es, asimismo, asociación creativa. Para Bolańo, el espacio de la parodia le permite reiterar, refutar y pervertir ciertos actos que acometen sus personajes, todos ellos ubicados en una suerte de eterno retorno que los hace, una y otra vez, asesinar, escribir, hacer el amor, leer, hablar, pensar. "El 'volver a contar' es una estrategia que cruza toda la narrativa de Bolaño y que se manifiesta tanto en el relato de historias referidas por otros, como en la vampirización de los propios textos", afirma Patricia Poblete Alday, en su libro Bolaño. Otra vuelta de tuerca (2010: 107). Se propone aquí una vuelta de tuerca más: sólo al volver a contar, en la repetición de un texto en otro contexto, en la parodia es como realmente se pueden apreciar los énfasis y subrayados que Bolańo desea hacer notorios en su propuesta literaria.

\section{Biografías que se vuelven a contar}

Algunos estudios han abordado la parodia en la literatura de Roberto Bolaño desde su novela más reconocida, Los detectives sal- 
vajes, y uno de sus motivos explícitos: la ridiculización o desacralización del establishment literario. ${ }^{2}$ No obstante, el empleo del procedimiento reiterativo, es decir, el modo de narrar algo conocido pero con otras modulaciones, aparece de forma significativa en los libros que comenzaron a darle cierto reconocimiento en vida: La literatura nazi en América y el ya citado Estrella distante, ambos publicados el año 1996.

Como se ha explicado en otros lugares ( $c f$. Ríos Baeza, 2013), La literatura nazi en América dialoga estrechamente en clave paródica con libros anteriores, como Vidas imaginarias, de Marcel Schwob, La sinagoga de los iconoclastas, de J. Rodolfo Wilcock y, sobre todo, con Historia universal de la infamia, de Jorge Luis Borges. En estos casos, lo parodiado no es tanto un archivo histórico, puente posible entre las biografías reales y las ficcionales, sino el género mismo que aguanta ese archivo. La utilización de un soporte canónico como el catálogo o catastro crítico, le aporta a Bolaño la estructura, pero ésta es pronto vulnerada por su mismo contenido, por lo que, así, queda desecha cualquier posibilidad de ser tomada como "género alto". En su ensayo "Repetición y parodia en La literatura nazi en América”, José Sánchez Carbó, uno de los primeros en abordar esta perspectiva, comenta que:

la biografía imaginaria como forma narrativa y las diversas expresiones literarias filo-fascistas de los personajes son los principales elementos de repetición. De estos se desprenden otro tipo de reiteraciones como la pertenencia espacial —el mismo continentey temporal —el siglo XX_, predominantemente; la presencia o la mención de ciertos personajes en varios relatos; y las editoriales y revistas en las que publican muchos de estos escritores [...]. Llama la atención cómo Bolańo estructura la biografía de sus perso-

${ }^{2}$ Pueden consultarse los trabajos primigenios de Grinor Rojo, «Sobre Los detectives salvajes» (2003) y Gloria Sepúlveda Villa "Parodia al canon literario en Los detectives salvajes de Roberto Bolaño” (2009). 
najes. Primero informa sobre peculiaridades o detalles biográficos para posteriormente describir el contenido o la estructura de la(s) obra(s) y su impacto en los lectores. Después de la exaltación aparentemente objetiva de la personalidad incorpora ya sea aspectos disonantes o infames (2011: 144).

Es la infamia, precisamente, - la que trastoca el género de la biografía literaria o catálogo de autor. Frente a instituciones y medios críticos defensores de una tradición literaria que expone y defiende la "condición humana", Bolaño contraviene ese criterio. La literatura nazi en América exhibe a treinta autores que, a pesar de tener un elevado gusto artístico y de elaborar una literatura tan atractiva que raya en la vanguardia, comparten el factor común de la ignominia política. Los escritores, al tiempo que desean fervorosamente consagrarse en el ámbito literario, pertenecen a las brigadas de la muerte, a las juventudes hitlerianas, a los aparatos represores de las dictaduras del Cono Sur de América Latina. Ésta es una parodia que no hace reír sino que extrańa, provoca afrenta, en tanto que se expone como paradoja fundamental: quien se dedica al arte — por lo general, de manera natural, moral e históricamente- estaba del lado de los derechos humanos. ¿Quién podría asumir a un poeta que guste asesinar mujeres en rituales sádicos o un novelista que abrace la causa común, por gusto, por placer, del antisemitismo? Este asunto lo desarrolla María José Bruña en su ensayo: "Roberto Bolaño: Formas del mal y posiciones intelectuales", donde se interesa por

rescatar al intelectual bolañiano de moral ambigua que, perteneciendo a cualquier época y país, no sólo no es crítico con el poder [...] sino que es cómplice perverso del mismo, debido, en la mayoría de los casos, a que se inscribe en coyunturas sociopolíticas extremadamente delicadas, como la dictadura, la guerra o una democracia agónica. Esta figura, dual y cuestionable, artista 
de extremada sensibilidad o librepensador, pero totalmente vil en lo que a sus actuaciones personales se refiere, habita las páginas de sus novelas [...]. Cada vez más lejos de la idea del "humanismo de la cultura” de Platón o Hegel, Bolaño sería más afín, entonces, a los planteamientos desengañados de Foucault, Steiner, Todorov o Sloterdijk (2010: 401-402).

Se da una actitud de plenitud artística, desde el foco del arte de vanguardia, y una condición de ignominia política, desde el foco de los derechos humanos, en un mismo tiempo y en un mismo espacio. Otro modo de verlo: lo que parece ser diáfano en el plano estético resulta siniestro en el plano social. Un ejemplo que viene muy bien al caso es el de la poeta pro-fascista Luz Mendiluce Thompson. Luego de una vida personal tormentosa, Mendiluce Thompson se casa con Mauricio Cáceres, poeta y colaborador de una revista, Letras Criollas, la que se empeña en impulsar el movimiento "neogauchesco", un término que opera, al fin, como eufemismo:

En 1961, y tras conseguir la anulación de su primer matrimonio, contrae nupcias con el poeta Mauricio Cáceres, colaborador de Letras Criollas y cultor de una poesía que él mismo denomina «neogauchesca». Escarmentada, esta vez Luz está decidida a ser una mujer ejemplar: deja Letras Criollas en manos de su marido (lo que le acarreará no pocos problemas con Juan Mendiluce, que acusa a Cáceres de ladrón), abandona la práctica de la escritura y se dedica en cuerpo y alma a ser una buena esposa. Con Cáceres al frente de la revista pronto los nazis, los resentidos y los problemáticos pasan, en masa, a ser «neogauchescos» (Bolańo, 2005a, 32-33).

Si, por un lado, la etiqueta de lo "neogauchesco" pretende esclarecer el panorama literario (agrupando a varios autores bajo un rubro y un reconocimiento), por otro enrarece el entorno social: ¿Cómo un nazi, un resentido, un problemático, puede escribir o 
reescribir literatura? ¿Tienen cabida, en un catálogo redentor de la excelencia artística, autores que no parecen estar del lado del humanismo? La paradoja de un "artista ignominioso" o de un "culto bárbaro" opera aquí para poner en evidencia un asunto central: que para establecer un canon, un género o un reconocimiento, los criterios que entran en juego exceden las meras coordenadas literarias y estéticas.

La legitimación de estos escritores socialmente corrosivos resulta hiperbólica en Estrella distante, una ampliación —una parodia - de "Ramírez Hoffman, el infame", personaje de la última parte de La literatura nazi en América. Específicamente, cuando el mencionado Bibiano O'Ryan, antiguo amigo del narrador y del artista-torturador Carlos Wieder, se propone escribir, en un guiño a Le Matin des Magiciens, de Bergier y Pauwels, un libro llamado El nuevo retorno de los brujos. Dicho volumen se presenta como "una antología de la literatura nazi americana. Un libro magno [...] que cubriría todas las manifestaciones de la literatura nazi en nuestro continente, desde Canadá (en donde los quebequeses podían dar mucho juego) hasta Chile, en donde seguramente iba a encontrar tendencias para todos los gustos" (Bolaño, 2003: 52). En otras palabras, se da a la tarea, en la textualidad, de fijar un corpus de autores elevados en el plano estético pero cuestionables en el plano ético; a la par, en la transtextualidad, parodia su libro anterior.

Por eso, la nota introductoria es elocuente: se trata, en palabras de Genette, de un hipertexto, Estrella distante, que resignifica un hipotexto, "Ramírez Hoffman, el infame". No obstante, para poder llevarse a cabo dicha operación de reiteración, el nuevo texto necesita ser escrito a dos y hasta a tres manos. Al comienzo, apunta Bolaño: "Esta historia me la contó mi compatriota Arturo B, veterano de las guerras floridas y suicida en África, quien no quedó satisfecho del resultado final" (2003:11). Tanto Bolaño como Arturo B intentan volver a contar una historia difícil, escurridiza, 
traumática de enunciar, pero se dan cuenta pronto que para ello requerirán de un tercero: "Mi función se redujo a preparar bebidas, consultar algunos libros, y discutir, con él y con el fantasma cada día más vivo de Pierre Menard, la validez de muchos párrafos repetidos" (2003: 11).

En efecto, en Estrella distante hay muchos párrafos repetidos de "Ramírez Hoffman, el infame"; sin embargo, según la lección aprendida de Pierre Menard, se diría: repetidos, mas no iguales, dando a entender que, como lo señalan posteriormente las distintas teorías intertextuales, la escritura es ante todo una repetición y una actividad artificiosa. El ejercicio de la escritura, en cuanto intertextualidad, equivale al desplazamiento o travestimiento, según Genette, de un discurso ya inserto en la tradición, que produce un efecto paródico al reconocerse, en primer lugar, una identidad anterior en ese "disfraz", y al señalarse, en segundo lugar, la orientación del cambio de contexto para con el texto. ${ }^{3}$ De este modo, si "Ramírez Hofmann, el infame" funcionaba como una entrada biográfica más en un catálogo de escritores simpatizantes del nacionalsocialismo, el hipertexto Estrella distante reitera algunos significantes de dicho hipotexto pero para encontrar significaciones distintas, en tanto novela autónoma.

El escurridizo feminicida de Estrella distante tiene al menos tres rostros que condicen con los momentos sociopolíticos que han marcado la historia reciente de Chile: durante el gobierno de Salvador Allende se le conoce como Alberto Ruiz-Tagle, un tímido versificador de los talleres literarios de Concepción; tras el golpe

\footnotetext{
${ }^{3}$ Apunta Genette: “¿Se puede concebir una transformación puramente semántica que no vaya acompañada de ninguna intervención pragmática, dietética, ni siquiera formal? Es, si recordamos, la apuesta de Borges cuando imagina a Pierre Menard reescribiendo por sus propios medios una nueva versión del Quijote rigurosamente idéntica en la letra a la de Cervantes, pero a la que dos siglos de historia por medio confieren mayor riqueza y profundidad, y un sentido muy otro; esta apuesta, ya lo he dicho, no es más que una monstruosa extensión del principio de parodia” (1989: 402-403).
} 
de Estado de 1973, se convertirá en Carlos Wieder, fotógrafo y poeta aéreo obsesionado con retratar y conjurar a sus víctimas; con el retorno a la democracia, a comienzos de la década de 1990, se le rastreará con el nombre de R. P. English, camarógrafo de películas pornográficas italianas de bajo presupuesto. Por lo tanto, y ésta quizás sea la propuesta más salvaje de Bolaño, entre un hipotexto y un hipertexto se visualiza no sólo la mano de Pierre Menard, sino la del Belano escritor; mano que intenta probar, también, un desplazamiento paródico adicional: llevar deliberadamente los géneros altos y canónicos, como la poesía, a otros más bajos y anticanónicos, como la pornografía.

Algo similar ocurre con el vínculo que tiene el libro de Los sinsabores del verdadero policía (2011) con algunos episodios de Estrella distante, Los detectives salvajes y "La parte de Amalfitano", de 2666. Sin embargo, de manera especial, interesa lo que acontece con Amuleto, novela de 1999 que narra la historia de Auxilio Lacouture, poeta uruguaya que durante la ocupación de la Universidad Nacional Autónoma de México en 1968 se queda encerrada en un baño y desde allí hace memoria. Dicha novela autonomiza un episodio que, como ha reconocido Myrna Solotorevsky, Bolaño ya había narrado en el capítulo 4 de Los detectives salvajes, aunque con funciones distintas:

Esta novela breve [Amuleto] es el producto de la extracción y expansión del capítulo 4 de Los detectives salvajes, la primera "meganovela" de Bolaño, una novela del post-boom, que tiende a la totalización. Nos encontramos así con la configuración de un hipertexto a partir de un hipotexto y con la expansión que ello conlleva. Se provocará como consecuencia un efecto de expansión semántica, de intensificación lírica y simbólica, y un reforzamiento de la proclamación ideológica [...]. El señalado tránsito del hipotexto al hipertexto ha puesto de manifiesto un rasgo que suele caracterizar a los textos de Bolaño, y que he denominado: "espesor 
escritural"; él consiste en la irradiación o proliferación de significados, a cuyo servicio se da "el ansia de narrar", el gozoso emerger de historias (Solotorevsky, 2010: 175, 198).

Estos reconocimientos paródicos confirman lo que Borges aseguraba sobre la reiteración del selecto párrafo del discurso de las armas y las letras en "Pierre Menard, autor del Quijote": puede haber coincidencias léxicas —el signo puede ser el mismo-, pero como los contextos de recepción han cambiado (del siglo XVI al XX, en el caso de Borges; de Amuleto al capítulo 4 de Los detectives salvajes, en el caso de Bolaño) ha cambiado también el sentido del signo. Patricia Poblete dice que "la estrategia de reduplicación exhibe en esta novela la imposibilidad de finiquitar el tiempo narrativo" (2010: 109), el cual ella marca con 2666; no obstante, dicha afirmación vale para el resto de los ejemplos vistos: ciertos episodios de las novelas de Bolaño no se agotan en el punto final porque el tiempo narrativo, que es lo mismo que decir el flujo literario, aún no se ha detenido, resemantizándose en cuentos, poemas, comentarios, libros posteriores.

\section{Espacios fronterizos: parodiando el ejercicio literario}

Si bien parece que Bolaño absorbe la literatura de otros autores del modo en que se ha entendido aquí la parodia (por ejemplo, Una novelita lumpen sería el reverso burlesco de las Tres novelitas burguesas, de José Donoso, y "El policía de las ratas" dialogaría de forma abierta y provechosa con "Josefina la cantora, o el pueblo de los ratones”, de Franz Kafka) el tránsito violento de un género canónico a uno anticanónico —-Belano mediante-, observado en Estrella distante en el trasvasije de la poesía al porno, será otro modo empleado por Bolaño para parodiar en su narrativa. 
¿Qué pasa cuando un signo (la literatura) se saca de su contexto habitual y se coloca en otros? ¿Dónde escriben y dónde leen los personajes de Bolaño, parodiando el tradicional ejercicio de la literatura acometido en talleres, aulas, torres de marfil? Se trata de asuntos que han sido sistematizados en momentos anteriores ( $c f$. Ríos Baeza, 2009; 2010), pero que conviene volver a traer aquí con el propósito de analizar de manera detenida uno de los usos más fructíferos que el chileno le da al "eslabón perdido" de Aristóteles. Bolaño no sólo saca un objeto literario de la tradición y lo vuelve a presentar travestido, al modo en que Genette entiende el asunto, sino que lo lleva a espacios más precarios, a escenarios menos habituales, para que desde ahí se vuelva a enunciar con otros significados. "Cantar a un costado", entonces, querría decir también cantar a la vera del camino, en los márgenes, alejado de los centros neurálgicos del poder, allí donde los enunciados aparecen controlados por el poder.

Tomar un género o un motivo sacralizado de la tradición literaria y desmenuzarlo hasta convertirlo en un lenguaje abierto, horizontal, recreativo, será una de las operaciones más significativas del Bolaño paródico. Aquí, la razón que se aventura para explicar dicha violencia epistemológica es el modo en que el chileno concibe la literatura: no se trata de un valor para un campo de saber específico, de élite intelectual, sino un devenir, un flujo que puede situarse en los espacios más inverosímiles.

La constante aparece ya en su primera novela, Consejos de un discípulo de Morrison a un fanático de Joyce, de 1984. Cuando el catalán Ángel Ros comienza a sentir los estragos del amorío desesperado que lo ata a Ana, su novia de origen sudamericano, busca refugio en los bares. En uno de esos sitios de ocio encuentra a un excéntrico grupo de hombres que, primero, muestran sus credenciales algo pendencieras sólo para, luego, exhibir las literarias: 
No me sorprendí cuando el alto, que era quien llevaba la voz cantante, anunció, mientras esperábamos en la barra la llegada de unas tapas de anchoa, su oficio de poeta.

Lo demás fue rápido y verosímil:

—Yo también soy poeta — dijo el marica bajito.

-Y yo — dijo su amigo, un chico gallego de unos veinte años, moreno y de ojos verdes.

- Bueno, yo también he escrito poesía — anuncié, no muy seguro de que me fueran a creer.

Al final todos éramos escritores: el larguirucho había publicado con su dinero un par de libros, los otros eran inéditos y marginales, aunque al bajito le habían publicado un poema en Camp de l'Arpa, antigua época, y el gallego, para mi sorpresa y beneplácito general, había sido incluido en una muestra de poesía visual que en esos días se exhibía en la única galería de arte de La Mina o algo parecido [...].

—Siéntate — dijo el gallego-. Estamos escribiendo un cadáver exquisito.

— Un cadáver exquisito! ¡Sí, me gusta! — gritó el largo, como si despertara (Bolaño y García, 2006: 101-102).

Es significativo que surja el debate artístico en un espacio en donde se le espera menos, que una galería tan abigarrada de personajes tenga contacto especial con los mecanismos de creación de una vanguardia como la dadaísta. ${ }^{4}$ Del mismo modo, el movimiento

${ }^{4}$ Se recuerda también, en esta perspectiva, las intenciones de Udo Berger en $E l$ Tercer Reich de convertirse en escritor, confesión otorgada en una playa fronteriza y dentro de una fortaleza creada por los patines que el Quemado le alquila a los veraneantes: "Ignoro qué impulso me hizo confesarle que pretendía ser escritor. El Quemado se giró y tras vacilar dijo que era una profesión interesante. Se lo hice repetir pues al principio creí malinterpretarlo./ —Pero no de novelas ni de obras de teatro-aclaré./ El Quemado entreabrió los labios y dijo algo que no pude escuchar./ —¿Qué?/ —¿Poeta?/ Debajo de sus cicatrices creí ver una especie de sonrisa monstruosa. Pensé que el sol me estaba atontando./ — No, no, 
de vanguardia realvisceralista de Los detectives salvajes surge también desde la marginalidad, desde las azoteas, desde las viviendas pobres, desde los habitáculos caóticos; al igual que la Escritura Bárbara, en Estrella distante, aquella práctica perpetrada en derruidos y minúsculos cuartos, comandada por un portero de nombre Raoul Delorme que pretendía erigir la quintaesencia de la humanización libresca, un método irrespetuoso pero necesario para democratizar el ejercicio literario. ${ }^{5}$

La relación, entonces, entre parodia y espacio fronterizo parece clara: el anquilosamiento discursivo e ideológico de los espacios céntricos no permite que la literatura alcance empresas mayores, cuando la literatura, según deducciones de la propia narrativa de Bolaño, ha tenido una histórica voluntad de actualizarse e indefinirse. Hay que recordar que varios personajes de Estrella distante,

por supuesto, poeta no./ Aclaré, ya que me había dado pie para ello, que yo no despreciaba en modo alguno la poesía. Hubiera podido recitar de memoria versos de Klopstock o de Schiller; pero escribir versos en estos tiempos, como no fueran para la amada, resultaba un tanto inútil, ¿̇no lo veía así?” (Bolaño, 2010: 79).

5 "Según Delorme, había que fundirse con las obras maestras. Esto se conseguía de una manera harto curiosa: defecando sobre las páginas de Stendhal, sonándose los mocos con las páginas de Víctor Hugo, masturbándose y desparramando el semen sobre las páginas de Gautier o Banville, vomitando sobre las páginas de Daudet, orinándose sobre las páginas de Lamartine, haciéndose cortes con hojas de afeitar y salpicando de sangre las páginas de Balzac o Maupassant, sometiendo, en fin, a los libros a un proceso de degradación que Delorme llamaba humanización. El resultado, tras una semana de ritual bárbaro, era un departamento o una habitación llena de libros destrozados, suciedad y mal olor en donde el aprendiz de literato boqueaba a sus anchas, desnudo o vestido con shorts, sucio y convulso como un recién nacido o más apropiadamente como el primer pez que decidió dar el salto y vivir fuera del agua. Según Delorme, el escritor bárbaro salía fortalecido de la experiencia y, lo que era verdaderamente importante, salía con una cierta instrucción en el arte de la escritura, una sapiencia adquirida mediante la 'cercanía real', la 'asimilación real' (como la llamaba Delorme) de los clásicos, una cercanía corporal que rompía todas las barreras impuestas por la cultura, la academia y la técnica" (Bolaño 2003, 139-140). 
entre ellos Bibiano O'Ryan y el narrador Bolaño, toman contacto con Carlos Wieder pocos ańos antes del golpe militar chileno, cuando el futuro poeta feminicida se hacía llamar Alberto RuizTagle y frecuentaba con complacencia los talleres de poesía de Diego Soto y Juan Stein, en la Universidad de Concepción. Bolaño registra del siguiente modo el entorno particular donde tiene lugar el taller de Soto: ${ }^{6}$

El taller de Soto estaba en la Facultad de Medicina, ignoro por qué razón, en un cuarto mal ventilado y mal amueblado, separado tan sólo por el pasillo del anfiteatro en donde los estudiantes despiezaban cadáveres en las clases de anatomía. El anfiteatro, por supuesto, olía a formol. El pasillo, en ocasiones, también olía a formol. Y algunas noches, pues el taller de Soto funcionaba todos los viernes de ocho a diez, aunque generalmente solía acabar pasadas las doce, el cuarto se impregnaba de olor a formol que nosotros intentábamos vanamente disimular encendiendo un cigarrillo tras otro (Bolaño, 2003: 20-21).

Nótese cómo el aroma del cigarrillo actúa para disfrazar una inminencia. A pesar de la estrechez del cuarto, el penetrante olor del aldehído fórmico se cuela, provocando una sensación de sofocamiento entre los concurrentes. Es interesante cómo Bolaño maneja este tipo de elementos como un indicio de lo que ocurrirá luego en esos espacios. Se sabe que el formol es utilizado en

${ }^{6}$ Pierre Pain, el mesmerista que protagoniza Monsieur Pain, siente la misma conmoción que Ángel Ros y que el narrador Bolaño de Estrella distante cuando identifica, en los albores de la revelación crucial de la novela, que el ejercicio literario puede tener cabida hasta en la taquilla de un cine, donde una pelirroja expende sin mucho afán los billetes: "—La película acaba de empezar- murmuró sin mirarme una mujer pelirroja algo entrada en carnes, más o menos de mi edad, que se entretenía en escribir algo en un cuaderno escolar cuya única peculiaridad era el color rosa de las hojas. ¡Versos! ¡Una poetisa! Saqué un billete y entré" (Bolaño, 2007a: 116). 
los hospitales para conservar muestras de tejidos e incluso para el embalsamamiento de los cadáveres; además, tiene propiedades anestésicas. Con estos antecedentes, es posible argumentar que ya desde las primeras páginas de Estrella distante, el espacio determina la configuración de la lógica narrativa y de las futuras prácticas de Wieder, quien conservará los cuerpos de varias de las mujeres asesinadas para retratarlas de cara a una exposición fotográfica y, al mismo tiempo, ayudar al régimen, con sus exhibiciones de poesía aérea, a mantener en un letargo el quehacer político y cultural chileno. Como puede adivinarse, los verdaderamente interesados en el ejercicio literario (O’Ryan, el propio Bolaño) huyen hacia las fronteras, donde desarrollan sus respectivos proyectos artísticos, alejados de un país donde los cuerpos, como en la Facultad de Medicina cercana al taller de Soto, se anestesian o se destazan.

Ahora bien, al igual que la escritura, los ejercicios de lectura y discusión literaria se revelarán, por necesidad o voluntad, también burlados desde los márgenes. Para varios de los personajes que circunstancialmente han debido habitar espacios restrictivos o decididamente marginales, la lectura tendrá una suerte de aura, de encontrada redención. ${ }^{7}$ ¿En qué lugares leen los personajes de Bolaño?, ¿por qué motivos? Enric Rosquelles, uno de los tres mo-

7 Se recordará la ponderación lectora, muy bartlebyana, que realiza el viejo escritor que le renta las máquinas de escribir a Benno von Archimboldi, en la última parte de 2666: "La lectura es placer y alegría de estar vivo o tristeza de estar vivo y sobre todo conocimiento y preguntas. La escritura, en cambio, suele ser vacío [...]. Llegó el día en que decidí dejar la literatura. La dejé. No hay trauma en este paso sino liberación. Entre nosotros le confesaré que es como dejar de ser virgen. ¡Un alivio, dejar la literatura, es decir dejar de escribir y limitarse a leer!» (Bolaño, 2004a: 983, 986). Asimismo, en un artículo recogido en Entre paréntesis llamado "Un escritor en la intimidad", Bolaño reconoce que lo natural de la literatura es leer, no escribir: "Leer, lo dijo Gil de Biedma, es más natural que escribir. Yo añadiría, pese a la redundancia, que también es mucho más sano, digan lo que digan los oftalmólogos. De hecho, la literatura es una larga lucha de redundancia en redundancia, hasta la redundancia final" (Bolaño, 2004b: 322). 
nologadores de la novela La pista de hielo aprende a leer "verdaderamente" en el espacio marginal de la cárcel, gracias a los libros que su ex mujer y su amor imposible le hacen llegar:

Ambas, Lola y Nuria, me dejaron sendos regalos. El de Lola era un libro de Remo Morán. El de Nuria, el libro por excelencia del patinaje, Santa Lydwina y la Sutileza del Hielo, de Henri Lefebvre, en edición francesa de Luna Park, Bruselas. Tanto para el hospitalizado como para el encarcelado no hay mayor presente que un libro. El tiempo es lo único que me sobra, aunque mi abogado dice que pronto estaré en la calle (Bolaño, 2004c: 167).

Es curioso cómo hasta el intelectualismo más elevado, representado por la figura de Henri Lefebvre (un referente crucial para el cuento "El viaje de Álvaro Rousselot", de El gaucho insufrible), puede aparecer en estos espacios. Para varios de los protagonistas, aquel acercamiento tan estrecho a lecturas complejas los desplaza desde aquel estado de adversidad hasta el comentado estado de redención. ${ }^{8}$ Si el ejercicio de la lectura ayudaba a Rosquelles a esperar

${ }^{8}$ Basta mencionar a Florita Almada, la vidente de "La parte de los crímenes" de 2666, que en medio de sus espacios de recreación mediados por el esoterismo, aprende a leer y a escribir y se convierte en una lectora omnívora: "Así es la vida, justo cuando ella creía que se desvanecían para siempre las posibilidades de estudiar o de retomar los estudios (vana esperanza, en Villa Pesqueira creían que Escuela Nocturna era el nombre de un burdel en las afueras de San José de Pimas), aprendió, sin grandes esfuerzos, a leer y a escribir. A partir de ese momento leyó todo lo que caía en sus manos. En un cuaderno anotó las impresiones y pensamientos que le produjeron sus lecturas. Leyó revistas y periódicos nuevos, leyó los pocos libros que pudo encontrar y su marido, después de cada ausencia traficando con animales en los pueblos vecinos, se acostumbró a traerle libros que en ocasiones compraba no por unidad sino por peso. Cinco kilos de libros. Diez kilos de libros. Una vez llegó con veinte kilos. Y ella no dejó ni uno sin leer y de todos, sin excepción, extrajo alguna enseñanza. A veces leía revistas que llegaban de Ciudad de México, a veces leía libros léperos que la hacían enrojecer, sola, sentada a la mesa, iluminadas las páginas por un quinqué 
en su celda la definitiva liberación, al joven B de "Últimos atardeceres en la Tierra", relato incluido en Putas asesinas, el contacto con los libros le permite continuar anclado a sus intereses de formación en un ambiente que, aunque no expresamente hostil, se percibe como cambiante y perturbador:

Antes de llegar a Acapulco el padre de B detiene el coche delante de un tenderete de la carretera. En el tenderete ofrecen iguanas. ¿Las probamos?, dice el padre de B. Las iguanas están vivas y apenas se mueven cuando el padre de B se acerca a mirarlas. B lo observa apoyado en el guardabarros del Mustang. Sin esperar respuesta, el padre de $\mathrm{B}$ pide una ración de iguana para él y para su hijo [...]. Entonces B desvía la mirada y vuelve a su libro, que permanece abierto sobre la mesa. Es un libro de poesía. Una antología de surrealistas franceses traducida al español por Aldo Pellegrini, surrealista argentino. Desde hace dos días B está leyendo este libro. Le gusta. Le gustan las fotos de los poetas. La foto de Unik, la de Desnos, la de Artaud, la de Crevel. El libro es voluminoso y está forrado con un plástico transparente. No es B quien lo ha forrado (B nunca forra sus libros) sino un amigo particularmente puntilloso. Así que B desvía la mirada, abre su libro al azar y encuentra a Gui Rosey, la foto de Gui Rosey, sus poemas, y cuando vuelve a levantar la mirada la cabeza de su padre ya no está (Bolaño, 2001: 38-39).

La mención, otra vez, a la vanguardia (esta vez por asimilación lectora y no por creación escritural) puede responder asuntos diver-

cuya luz parecía bailar o adoptar formas demoniacas, a veces leía libros técnicos sobre el cultivo de viñedos o sobre construcción de casas prefabricadas, a veces leía novelas de terror y de aparecidos, cualquier tipo de lectura que la divina providencia pusiera al alcance de su mano, y de todos ellos aprendió algo, a veces muy poco, pero algo quedaba, como una pepita de oro en una montańa de basura, o para afinar la metáfora, decía Florita, como una muñeca perdida y reencontrada en una montańa de basura desconocida” (Bolaño 2004a, 539). 
gentes. Tanto el hecho de haberse detenido en un puesto exótico donde venden carne de iguana como el creciente interés del joven B por la figura de Gui Rosey, ponen la atención en el movimiento que los personajes realizan de los centros hacia los bordes, alteración que modificará significativamente su percepción e identidad.

Es fundamental el aprecio de B por Gui Rosey, un poeta menor que de un momento a otro desaparece del inmediato círculo surrealista, cuyo paradero, si bien en un comienzo genera intriga, nadie después se anima a descubrir (al igual que Ulises Lima, que desaparece de la delegación que viaja a Nicaragua en la segunda parte de Los detectives salvajes, y que Henri Simon Leprince, otro poeta menor que luego de ayudar a los poetas de la resistencia tras la capitulación francesa, durante la Segunda Guerra Mundial, se esconde sin dejar rastro). El viaje que $\mathrm{B}$ realiza con su padre desde el DF hasta Acapulco conlleva la misma sutil disolución de la identidad del muchacho, que en un principio desea seguir anclado a su pasatiempo lector, pero que en los puestos de comida, en los hoteles y luego en los lupanares va articulando un interés vivo por el paisaje marginal al que accede. En suma, la literatura en los espacios marginales, además de ayudar a desacralizar la práctica, resultará constitutiva como oficio transfigurador para quienes se atreven a asumirla cabalmente.

La literatura, por lo tanto, aparece en las fronteras como una alarma que advierte el desmantelamiento de algún aspecto traído o sostenido desde el centro. No es gratuito, entonces, que los personajes de Bolaño lean hasta en los frentes de batalla, cuando el desmoronamiento de las tropas y las líneas de combate es inminente, como en el caso paródico de un oficial del batallón donde lucha el joven Hans Reiter, cuando aún no sueña en convertirse en Benno von Archimboldi. El narrador de 2666 reseña:

Cerca del ordenanza y del oficial que miraba la disposición que el ordenanza daba a las viandas sobre la mesa se encontraba, de 
espaldas a todos, otro oficial, éste con el uniforme de la Luftwaffe, aburrido de ver pasar a los aviones, que sostenía en una mano un largo cigarrillo y en la otra un libro, una operación sencilla pero que a este oficial de la Luftwaffe parecía costarle ímprobos esfuerzos pues la brisa que soplaba sobre la loma en donde estaban todos le levantaba constantemente las hojas del libro, impidiéndole la lectura, lo que llevaba al oficial de la Luftwaffe a utilizar la mano que sostenía el largo cigarrillo para mantener fijas (o inmóviles o quietas) las hojas del libro levantadas por la brisa, cosa que no conseguía sino empeorar la situación pues el cigarrillo o la brasa del cigarrillo tendía indefectiblemente a quemar las hojas del libro o la brisa desparramaba sobre las hojas le ceniza del cigarrillo, lo que molestaba mucho al oficial, que entonces inclinaba la cabeza y soplaba, con mucho cuidado, pues se encontraba de cara al viento y al soplar la ceniza corría el riesgo de que ésta terminara alojada en sus ojos (Bolaño, 2004a: 838).

Como en los casos anteriores, la lectura en sitios no habituales es asumida como un aliciente y un mecanismo tenue para que los personajes vayan accediendo, dócilmente, a las zonas marginales de diseminación. En este caso, por muy gracioso que parezca, lo volátil y peligroso de las cenizas del cigarrillo permite aventurar el inicio de las peripecias del batallón de Reiter, una unidad que se caracteriza por su mutabilidad y contingencia. En el futuro, cuando se repiten las circunstancias, la tropa tiene numerosas bajas y transformaciones. Finalmente, en el frente rumano, las cenizas se alojan irremediablemente en los ojos de los oficiales. No obstante, gracias a la lectura de los papeles de un tal Borís Abramovich Ansky (unos cuadernos rescatados en las ruinas de una aldea enemiga), Hans Reiter se moviliza, otra vez, hacia espacios fronterizos.

El cuento "Músculos", de El secreto del mal (2007), responde a la misma lógica. Este relato, antecedente o esqueleto de Una novelita lumpen, presenta a Marta y Enric, dos huérfanos que, como sus equivalentes de la novela citada, comparten las labores de la casa 
y la afición por los programas de televisión. Enric es un mecánico decidido a destacarse en el fisicoculturismo; Marta trabaja como peluquera y es la narradora del relato. A pesar de realizar actividades que, se supondría, son incompatibles con los altos debates intelectuales, por las mañanas los hermanos comentan paródicamente sus lecturas de filosofía antigua. Es importante subrayar cómo varios de los sistemas filosóficos tienen correlato en la cultura de masas, puesto que es otra de las estrategias textuales que emplea Bolaño cuando demuestra su incordio hacia el canon:

Generalmente hablábamos de los filósofos presocráticos a la hora del desayuno. A él el que más le gustaba era Empédocles. Este Empédocles, afirmaba, es como Spiderman. A mí, Heráclito. No sé por qué casi nunca hablábamos de filósofos por la noche. Debía de ser porque por la noche teníamos muchas más cosas de las que hablar o porque a veces llegábamos demasiado cansados de nuestros respectivos trabajos y hablar de filosofía requiere una mente fresca [...]. Sobre esa mesa mi hermano extendía el fascículo de algún presocrático (su obra completa) o alguna revista y mientras con la mano derecha manejaba la cuchara o el tenedor, con la izquierda daba vueltas a las páginas.

- Mira lo que pensaba el cabrón de Diógenes de Apolonia.

Yo me quedaba callada y aguardaba sus palabras intentando componer una expresión atenta.

- «Al comenzar un tema cualquiera me parece que es necesario ofrecer un principio indiscutible y una forma de expresión sencilla y decorosa.» Ni más ni menos.

- Suena razonable.

—-Joder si es razonable (Bolaño, 2007b: 129, 130-131).

De este modo se produce el efecto paródico: las formas "sencillas" y "decorosas" de expresión son conducidas a través de soportes no tradicionales para quien decide acercarse con esa solemnidad, que a Bolaño le parecía no sólo absurda sino canallesca, a la filosofía. 
El fascículo o la revista, publicaciones relegadas a la mera difusión e incluso al aligeramiento de las ideas, trastocan el libro como un gran soporte de saber para la comprensión e importancia de las propuestas filosóficas. La elección de un formato "menor" (como anteriormente el interés por poetas "menores" y los géneros "menores") responde a una ideología lectora, anticanónica, irrespetuosa, marginal; todos ellos elementos nucleares del ideario textual de Bolaño.?

Literatura presente en cárceles, en los frentes de batalla, en puestos de comida exótica, en peluquerías, en playas y talleres mecánicos. Tal vez el caso más emblemático del procedimiento lector en la narrativa de Bolaño sea el de un farmacéutico amigo del profesor chileno Óscar Amalfitano, en 2666. Cuando Rosa aún vivía con Amalfitano en Barcelona, antes de marcharse a San Sebastián, cerca de su casa había una farmacia. Mientras estaba de turno, la atendía un joven muy delgado de grandes gafas (¿Belano?), quien pernoctaba teniendo constantemente un libro en las manos. Una noche, Amalfitano se atrevió a preguntarle por sus preferencias literarias. Su respuesta representa uno de los momentos más luminosos de toda la narrativa de Bolaño:

Escogía La metamorfosis en lugar de El proceso, escogía Bartleby en lugar de Moby Dick, escogía Un corazón simple en lugar de Bouvard y Pécuchet, y Un cuento de Navidad en lugar de Historia de dos

${ }^{9}$ La actitud poco reverencial hacia la antigüedad griega se visualiza en otro momento de "Músculos", cuando Enric, el hermano, aparece en casa con dos latinoamericanos. Marta se molesta un tanto y se retira a su habitación a leer ni más ni menos que al fundador de la escuela eleática, uno de los oponentes de la visión multi-divínica descrita por Homero y Hesíodo, Jenófanes de Colofón, otro desacralizador: "Terminé de cenar antes que ellos y me encerré en mi habitación [...]. No tenía sueño. Me saqué los zapatos y me tiré en la cama, vestida, con la obra completa de Jenófanes de Colofón ('de la tierra nace todo y en tierra todo acaba'), hasta que los oí levantarse de la mesa” (Bolaño, 2007b: 139). 
ciudades o El Club Pickwick. Qué triste paradoja, pensó Amalfitano. Ya ni los farmacéuticos ilustrados se atreven con las grandes obras, imperfectas, torrenciales, las que abren caminos a lo desconocido. Escogen los ejercicios perfectos de los grandes maestros. O lo que es lo mismo: quieren ver a los grandes maestros en sesiones de esgrima de entrenamiento, pero no quieren saber nada de los combates de verdad, en donde los grandes maestros luchan contra aquello, ese aquello que nos atemoriza a todos, ese aquello que acoquina y encacha, y hay sangre y heridas mortales y fetidez (Bolaño, 2004a: 289-290).

Ante todo, es importante señalar que esta cita opera dentro del texto como una reflexión y casi una justificación paródica del libro mismo, 2666. En sus últimos años, Roberto Bolaño tendía a provocar el debate, tanto referencial como teórico, en torno a la novela como género acumulativo y torrencial, en contraposición al cuento. En el afán de seguir abriendo los límites establecidos, el escritor esbozó en varios momentos de su dietario la noción de la novela como pura y peligrosa fluidez y del cuento como un atractivo y necesario ejercicio técnico. En "Consejos sobre el arte de escribir cuentos", incluido en Entre paréntesis, dejó apuntado: "Voy a dar algunos consejos sobre el arte de escribir cuentos. Nunca aborde los cuentos de uno en uno. Si uno aborda los cuentos de uno en uno, honestamente, uno puede estar escribiendo el mismo cuento hasta el día de su muerte [...]. Lo mejor es escribir los cuentos de tres en tres, o de cinco en cinco. Si se ve con la energía suficiente, escríbalos de nueve en nueve o de quince en quince" (Bolaño, 2004b: 324).

Esta propuesta revela la agudeza con que el autor asume el género de la narrativa breve, plausible de detenerse al alcanzar un determinado número de páginas o de cuantificarse para, en sintonía con otros relatos, incluirse en un volumen. Son las "sesiones de esgrima de entrenamiento", los momentos en los que el riesgo (un 
riesgo estético y ético a la vez) se ve disminuido. "Los riesgos, en literatura, son de orden ético, básicamente ético, pero no pueden expresarse si no se asume un riesgo formal", comentó en una entrevista. "De hecho, en todos los ámbitos de la vida la ética no puede expresarse sin la asunción previa de un riesgo formal" (Braithwaite, 2006: 77). De esta manera, el escritor parece vislumbrar el potencial aún en ciernes de la novela en contraposición con el cuento, limitado como género debido a sus económicas posibilidades de creación y al estudio academicista y estético dominante (bastará recordar la separación tradicional, con olor a taller literario, entre el cuento cortazariano, cerrado y redondo, y el cuento chejoviano, abierto e interrumpido). La novela, entonces, como escenario de combate, como peligroso juego de apuestas totales, importó a Bolaño tanto en su condición de exhibición de temáticas recurrentes como en su exploración o adaptación de formas narrativas novedosas. Las cinco partes de 2666, saturadas de vasos comunicantes, o la polifonía de voces de la segunda parte de Los detectives salvajes, sólo por nombrar sus novelas más "riesgosas", son buenos ejemplos de lo descrito.

En este sentido, y volviendo al ejemplo del ilustrado farmacéutico de "La parte de Amalfitano", parece sustancial que un lector aficionado, que disfruta de los libros en un espacio no tradicional, se acerque a los "entrenamientos" de los grandes maestros. Los combates descampados, los saltos espectaculares donde por lo general quedan expuestas las fisuras de los recursos narrativos de los grandes escritores, son dejados, paradójicamente pero sin pena, a condición de que la academia y la crítica los examine sin disfrute. Por esto, la figura del joven farmacéutico encarna una propuesta lectora interesante. Afirma Roland Barthes, en El placer del texto: "La avidez misma del conocimiento nos arrastra a sobrevolar o a encabalgar ciertos pasajes (presentados como 'aburridos') para reencontrar lo más rápidamente posible los lugares quemantes de 
la anécdota” (20). Según la lección que otorga el crítico francés, el placer lector parece estar reñido con la edificación de una metodología de lectura en un espacio pretendidamente céntrico, que anquilosa y reverencia a autores eximios y a sus predicados, las obras maestras. Cabe la posibilidad de que, en su posición limítrofe, en una posición más acorde para parodiar, el acto de destacar una obra y fijarla para la posteridad sea para el farmacéutico una opción aún más peligrosa que la contracultura. En palabras de Barthes: "Ni la cultura ni su destrucción son eróticos: es la fisura entre una y otra la que se vuelve erótica [...]. Texto de placer: el que contenta, colma, da euforia; proviene de la cultura, no rompe con ella y está ligado a una práctica confortable de la lectura" (2007: 15, 25).

Por eso, sin objetar ni preferir espacio alguno, los personajes de Bolaño están constantemente leyendo desde una posición que les permite descomprimir la tensión canónica de dichas obras, parodiándolas, resignificándolas, volviéndolas a contar.

\section{Fuentes}

Barthes, Roland, 2007, El placer del texto, México, Siglo XXI.

Bolaño, Roberto, Amuleto, Barcelona, Anagrama.

,2001, Putas asesinas, Barcelona, Anagrama.

, 2003, Estrella distante, Barcelona, Compactos Anagrama.

, 2004a, 2666, Barcelona, Anagrama.

, 2004b, Entre paréntesis, Barcelona, Anagrama.

, 2004c, La pista de hielo, Barcelona, Seix Barral.

, 2005a, La literatura nazi en América, Barcelona, Seix Barral.

, 2005b, Los detectives salvajes, Barcelona, Compactos Anagrama. 
, 2007a, Monsieur Pain, Barcelona, Anagrama.

, 2007b, El secreto del mal, Barcelona, Anagrama.

, 2010, El Tercer Reich, Barcelona, Anagrama.

y Antoni García Porta, 2006, Consejos de un discípulo de Morrison a un fanático de Joyce, Barcelona, Acantilado.

Braithwaite, Andrés (comp.), 2006, Bolaño por sí mismo. Entrevistas escogidas, Santiago de Chile, Ediciones Universidad Diego Portales.

Bruña Bragado, María José, 2010, “Roberto Bolaño: Formas del mal y posiciones intelectuales”, en Felipe A. Ríos Baeza (ed.), Roberto Bolaño: Ruptura y violencia en la literatura finisecular, México, Eón, pp. 399- 418.

Genette, Gérard, 1989, Palimpsestos. La literatura en segundo grado, Madrid, Taurus.

Poblete Alday, Patricia, 2010, Roberto Bolaño: Otra vuelta de tuerca, Santiago de Chile, Universidad Academia de Humanismo Cristiano.

Ríos Baeza, Felipe A., 2013, Roberto Bolaño: Una narrativa en el margen. Desestabilizaciones en el canon y la cultura, Valencia, Tirant Lo Blanch.

, 2010, "Los lados B de B. Una aproximación a lo anticanónico en la narrativa de Roberto Bolaño", en Felipe A. Ríos Baeza (ed.), Roberto Bolaño: Ruptura y violencia en la literatura finisecular, México, Eón, pp. 107-140.

, 2009, "Los poetas bajaron del Olimpo: El motivo de la desacralización literaria en el volumen Llamadas telefónicas, de Roberto Bolaño", en Alejandro Palma Castro y Felipe A. Ríos Baeza (eds.), Con/versiones en la literatura hispanoamericana, México, BUAP, pp. 91-102. 
Rojo, Grinor, 2003, “Sobre Los detectives salvajes” en Patricia Espinosa (comp.), Territorios en fuga: Estudios criticos sobre la obra de Roberto Bolaño, Santiago de Chile, Frasis, pp. 65-75.

Sánchez Carbó, José, 2011, "Repetición y parodia en La literatura nazi en América", en Felipe A. Ríos Baeza y Francisco Javier Romero Luna et al. (eds.), Memorias electrónicas del I Congreso Internacional de Literatura Hispanoamericana Contemporánea: Roberto Bolaño, México, BUAP, pp. 141-146.

Sepúlveda Villa, Gloria, 2009, "Parodia al canon literario en Los detectives salvajes de Roberto Bolaño", disponible en: http:// es.scribd.com/doc/62698738/Parodia-Al-Canon-Literarioen-Los-detectives-salvajes-de-Roberto-Bolano (cosultado el $1 / \mathrm{X} / 2013)$.

Sklodowska, Elzbieta, 1991, La parodia en la nueva novela hispanoamericana (1960-1985), Amsterdam-Philadelphia, John Benjamins Publishing Company.

Solotorevsky, Myrna, 2010, “Amuleto, de Roberto Bolaño: expansión de un hipotexto", en Felipe A. Ríos Baeza (ed.), Roberto Bolaño: Ruptura y violencia en la literatura finisecular, México, Eón, pp. 175-200.

(Artículo recibido el 21 de enero de 2014; aceptado el 24 de marzo de 2014) 
